\title{
Low Plasma Estradiol is Required for the Expression of Daily Increase in Plasma Gonadotropins in the Lactating Golden Hamster (Mesocricetus auratus)
}

\author{
Hisashi KISHI, Toshiyuki OKADA, Mariko OTSUKA, \\ Gen WATANABE, Kazuyoshi TAYA and Shuji SASAMOTO
}

Laboratory of Veterinary Physiology, Tokyo University of Agriculture and Technology, 3-58 Saiwai-cho, Fuchu-shi, Tokyo 183, Japan

\begin{abstract}
Mechanisms responsible for a daily increase in plasma gonadotropins during lactation of golden hamsters (Mesocricetus auratus) were investigated. A daily afternoon (1700 h) increase in plasma luteinizing hormone (LH), follicle-stimulating hormone (FSH) and progesterone was observed until at least day 15 of lactation (day 0 of lactation = day of parturition). On the other hand, plasma estradiol did not show any significant change at 1100, 1700 and $2300 \mathrm{~h}$. Such increases occur in hamsters nursing 8 pups. In hamsters nursing 2 pups, however, only a daily increase in LH was noted on day 5 of lactation and the diurnal rhythm of LH was difficult to see because of the increase in basal levels of LH on day 10 and 15 of lactation. The diurnal increases in plasma LH and FSH disappeared within 2 days after removal of the litter on day 10 of lactation and by day 14 of lactation (4 days after litter removal) most animals had resumed ovulating. Ovariectomy on day 2 of lactation did not affect the profile of plasma LH on subsequent days. In contrast, the basal levels of plasma FSH increased, suggesting the absence of an inhibitory ovarian signal (probably inhibin). A negative relationship existed between plasma estradiol and the daily surges of LH and FSH at $1700 \mathrm{~h}$; the daily rise in gonadotropins occurred when plasma levels of estradiol were low. The afternoon increases in plasma LH and FSH were prevented by treatment with physiological levels of estradiol, comparable to those observed in the cyclic hamster. Antiserum against LHRH injected at $1100 \mathrm{~h}$ on day 10 of lactation completely suppressed the daily rise of plasma LH and FSH. These results indicate that during lactation low levels of estradiol are required for the expression of diurnal increase in plasma LH and FSH in the hamster. Moreover, the low levels of estradiol results in the daily release of LHRH.
\end{abstract}

Key words: LH, LHRH, Estradiol, Lactation, Golden hamster

(J. Reprod. Dev. 43: 129-136, 1997)

$\mathrm{n}$ the female golden hamster (Mesocricetus aura$t u s)$, characteristic daily increases in plasma levels of luteinizing hormone (LH) and follicle-stimulating hormone (FSH) are observable every afternoon during lactation, but not during pregnancy or pseudopregnancy [1]. After parturition,

Accepted for publication: January 20, 1997

Correspondence: K. Taya follicular atresia and luteolysis occur rapidly and the ovaries are transformed into an almost solid mass of interstitial tissue [2]. Therefore, there are no antral follicles and functional corpora lutea in the ovary of lactating hamsters. During lactation in hamsters, plasma estradiol and progesterone are usually low; whereas, there are daily increase in plasma levels of FSH and LH. The LH elevation is presumably responsible for the interstitial hyper- 
plasia and daily afternoon increase in progesterone $[3,4]$. The diurnal rhythm in plasma levels of LH and FSH is also observable in photoinduced anovulatory [5], melatonin-induced anovulatory [6], monosodium glutamate-sterilized [7] and immature hamsters [8,9]. All these hamsters have almost the same ovarian structure and function as well as lactating hamsters. In this study, the mechanism responsible for the diurnal increase in gonadotropins was investigated in animals with suppressed ovarian activities. The animals investigated were lactating hamsters and special attention was given to estradiol and $\mathrm{LH}$ releasing hormone (LHRH).

\section{Materials and Methods}

\section{Animals}

Adult female golden hamsters, raised in Laboratory of Veterinary Physiology, the Tokyo University of Agriculture and Technology, were used in this study. Animals were maintained under controlled temperature and lighting (lights on from 0500 to $1900 \mathrm{~h}$ ). The 4-day estrous cycle was monitored by characteristic vaginal discharge on the morning of the day of ovulation, which was designated as day 1 of the cycle. Females that had previously exhibited at least 2 consecutive estrous cycles were caged overnight with a male on the afternoon of day 4 (proestrus). The subsequent day was designated as day 0 of pregnancy. The expectant mothers were kept 4-6 animals per cage before day 12 of pregnancy and then caged individually thereafter. The day of parturition was designated as day 0 of lactation and the litter of each female was adjusted to 8 or 2 pups on day 1 of lactation.

Experiment 1. Changes in plasma levels of $\mathrm{LH}$, FSH, progesterone, estradiol and inhibin

Lactating animals with 8 pups were bled via the jugular vein, under light ether anesthesia, at 1100, 1700 and 2300 h on days 5, 10, 15 or 20 of lactation. Mothers with 2 pups were also bled via the jugular vein at 1100,1700 and $2300 \mathrm{~h}$ on days 5,10 or 15, but not on day 20 of lactation. Bleeding was performed at only one time from individual animals in this and in subsequent experiments.
Experiment 2. Effects of removing the litter on plasma levels of hormones

Eight pups were removed from lactating animals at $1100 \mathrm{~h}$ on day 10 of lactation. The mothers were then bled from the jugular vein under light ether anesthesia at 1100, 1700 and $2300 \mathrm{~h}$ on subsequent days until day 15 post partum, and the reappearance of vaginal discharge (characteristic of day 1 of the cycle) was monitored. Intact lactating animals with 8 pups were also bled on the same schedule as controls.

Experiment 3. Effects of ovariectomy on the daily increase in plasma LH and FSH

Lactating hamsters suckling 8 pups were ovariectomized on the morning of day 2 of lactation. They were bled from the jugular vein at 1100, 1700 and $2300 \mathrm{~h}$ on days 5,10 and 15 of lactation.

Experiment 4. Effects of an estradiol implant on daily changes in plasma levels of LH and FSH

Lactating animals with 8 pups were ovariectomized on the morning of day 2 and implanted subcutaneously with a Silastic capsule tube (1.57 $\mathrm{mm}$ inner diameter, $3.18 \mathrm{~mm}$ outer diameter $\times 10$ mm; Dow Corning Corporation Medical Products, MI, U.S.A.) containing estradiol (1, 3, 5 (10)-estratriene-3, 17 $\beta$-diol, Teikoku Hormone Co. Ltd., Tokyo, Japan) or an empty capsule. Blood samples were collected at 1100, 1700 and $2300 \mathrm{~h}$ on day 5 of lactation. Plasma concentrations of estradiol after estradiol implant were within the physiological levels of the cyclic hamster.

Experiment 5. Effects of passive immunization against LHRH on daily changes in gonadotropins

Two hundred $\mu \mathrm{l}$ antiserum against LHRH (LHRH-AS) was injected into lactating animals (with 8 pups) through the jugular vein under light ether anesthesia at $1100 \mathrm{~h}$ on day 10 of lactation. The animals were bled just before treatment with LHRH-AS and at 1700 and $2300 \mathrm{~h}$ on the same day.

The LHRH-AS was the same preparation described previously [10]. A biological activity test, using this antiserum, showed that $200 \mu \mathrm{l} \mathrm{LHRH}-$ AS given to hamsters at $1100 \mathrm{~h}$ on the morning of day 4 of the estrous cycle completely inhibited ovulation on the subsequent morning. Rat LH, FSH and prolactin showed no cross-reaction with 
LHRH-AS in radioimmunoassays (RIAs). Control serum was obtained from a castrated goat immunized against bovine serum albumin.

Determinations of plasma levels of LH, FSH, prolactin, inhibin, estradiol and progesterone.

Blood samples were centrifuged immediately after bleeding and plasma was separated and stored at $-20 \mathrm{C}$ until assayed for 6 different hormones. The determination of each hormone was carried out by specific RIAs.

Concentrations of plasma LH, FSH and prolactin were measured using NIDDK RIA kits for rat LH, FSH and prolactin as described previously [11]. Iodinated preparations were rat LH-I-7, FSH-I-7 and PRL-I-5. The antisera used were anti-rat LHS-10, FSH-S-11 and PRL-S-9. Results were expressed in terms of NIDDK rat LH-RP-2, FSHRP-2 and PRL-RP-2. The intra- and inter-assay coefficients of variation were $5.3 \%$ and $14.9 \%$ for $\mathrm{LH}, 6.3 \%$ and $14.6 \%$ for $\mathrm{FSH}$, and $9.8 \%$ and $17.9 \%$ for prolactin respectively.

Plasma concentrations of inhibin were measured using a method described previously [12]. Briefly, the iodinated preparation was a $32 \mathrm{KDa}$ bovine inhibin purified from bovine follicular fluid and the antiserum was a rabbit antiserum against bovine inhibin (TNDH-1), as described previously [13]. Results were expressed in terms of $32 \mathrm{KDa}$ bovine inhibin. The intra- and inter-assay coefficients of variation were $6.9 \%$ and $12.0 \%$ respectively.

Plasma concentrations of estradiol and progesterone were determined by double-antibody RIA systems using ${ }^{125}$ I-labeled radioligands as described previously [14]. Antisera against estradiol (GDN 244 [15]) and progesterone (GDN 337 [16]) were provided by Dr. G. D. Niswender (Colorado State University, Fort Collins, CO, U.S.A.). The intraand inter-assay coefficients of variation were $3.7 \%$ and $6.2 \%$ for estradiol and $6.3 \%$ and $15.4 \%$ for progesterone respectively.

\section{Statistics}

All data were expressed as mean \pm S.E.M. The significance between two means was analyzed by using the Student's t-test or Cochran-Cox test and a value of $P<0.05$ was considered statistically significant.

\section{Results}

Experiment 1. Changes in plasma levels of LH, FSH, progesterone, estradiol and inhibin (Figs. 1 and 2)

The diurnal change in plasma levels of 5 hormones on days 5, 10, 15 and 20 of lactation is shown in Fig. 1. In animals nursing 8 pups, plasma levels of LH were typically low at 1100 and $2300 \mathrm{~h}$ and significantly $(P<0.05)$ elevated at $1700 \mathrm{~h}$ on each day except day 20 of lactation (Fig. 1a). The increased levels of LH at $1700 \mathrm{~h}$ on each day (1.20 $\mathrm{ng} / \mathrm{ml}$ on day $5 ; 1.30 \mathrm{ng} / \mathrm{ml}$ on day $10 ; 1.10 \mathrm{ng} / \mathrm{ml}$ on day 15) were significantly low compared with the peak value during the preovulatory LH surge during the estrous cycle $(10.32 \mathrm{ng} / \mathrm{ml})$. Diurnal increases in plasma levels of FSH and progesterone were also noted at $1700 \mathrm{~h}$ on each day of lactation except day 20 of lactation (Fig. $1 \mathrm{~b}$ and 1c). On the other hand, no rhythms were observed in the low levels of estradiol (Fig. 1d). The diurnal release of inhibin occurred only on day 5 of lactation and thereafter there was no rhythmical pattern (Fig. 1e). Diurnal changes in plasma levels of prolactin were not observed throughout the experiment (data not shown).

In mothers nursing 2 pups, a diurnal rhythm was noted only for LH on day 5 of lactation and it was difficult to see because of the increase in basal levels of LH. No diurnal increase was observed in the other hormones.

Values of plasma LH or FSH and estradiol at $1700 \mathrm{~h}$ in animals suckling 2 or 8 pups were plotted on two-parameter histograms (Fig. 2a and 2b). The graphs clearly showed that the samples fell into two groups. The first group showed high concentrations of LH and FSH and low levels of estradiol, whereas, the other group showed low concentrations of LH and FSH and high levels of estradiol.

Experiment 2. Effects of removing the litter on plasma levels of hormones (Fig. 3)

A vaginal discharge was noted in most animals within 4 days after removing the litter and these animals began to show an estrous cycle similar to that of normal hamsters.

Plasma levels of LH obtained after litter removal showed considerable variation after 2 days and the significant differences between the values found at $1700 \mathrm{~h}$ and at 1100 and $2300 \mathrm{~h}$ were no longer 


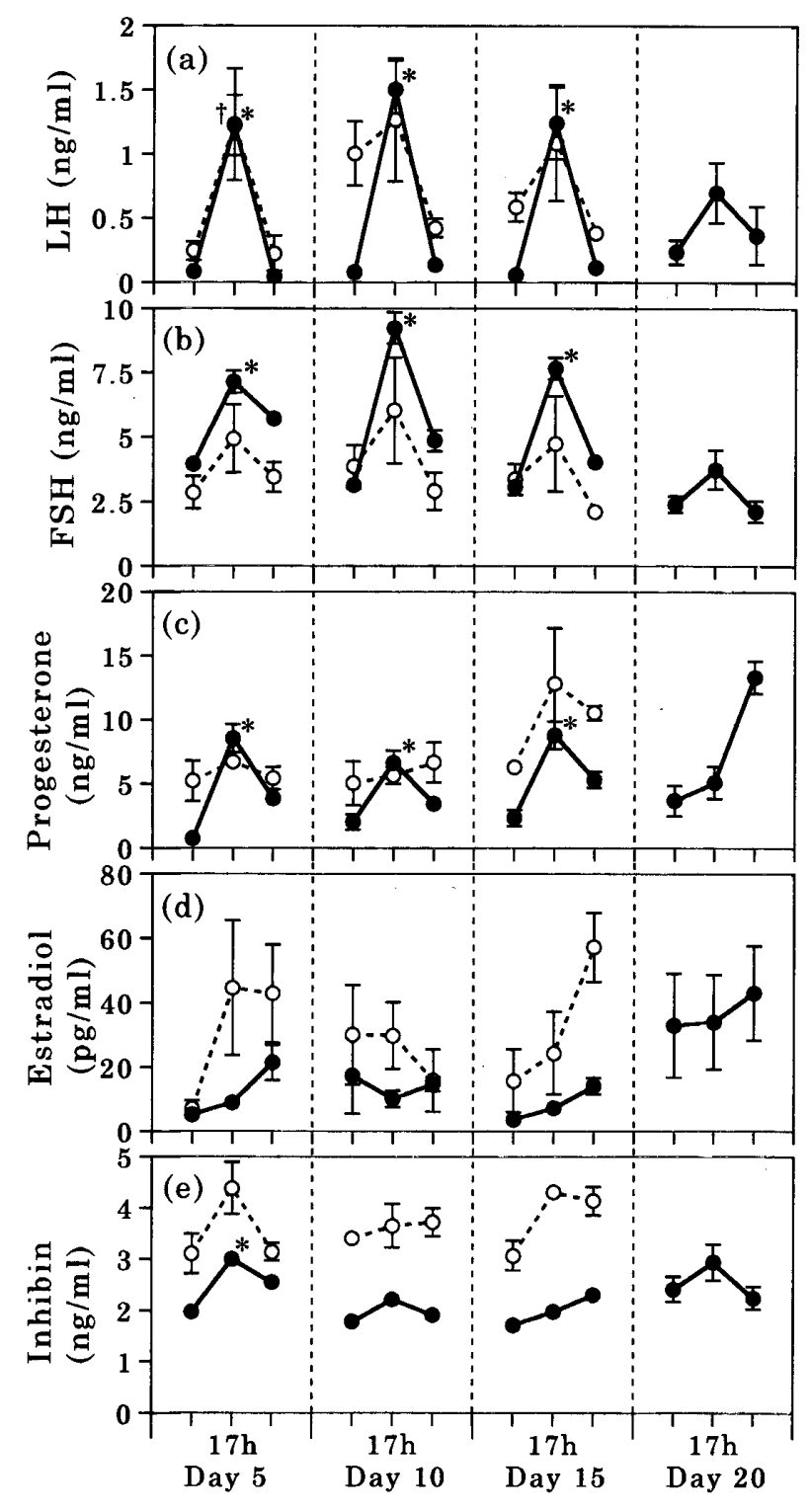

Hours and days of lactation

Fig. 1. Diurnal changes in plasma concentrations of (a) LH, (b) FSH, (c) progesterone, (d) estradiol, and (e) inhibin on days $5,10,15$ and 20 of lactation in mothers with 8 pups (O) or mothers with 2 pups $(\bigcirc)$. Each value represents mean \pm S.E.M. of five animals. ${ }^{*}$ refers to a statistical difference $(P<0.05)$ in the values at $1700 \mathrm{~h}$ compared with the values at $1100 \mathrm{~h}$ on the same day in the group with 8 pups. $\dagger$ refers to a statistical difference $(P<0.05)$ in the values at $1700 \mathrm{~h}$ compared with the values at 1100 $\mathrm{h}$ on the same day in the group with 2 pups.

present (Fig. 3a). The effect of removing the suckling stimulus on daily changes in plasma levels of FSH was more clear and the daily increase was

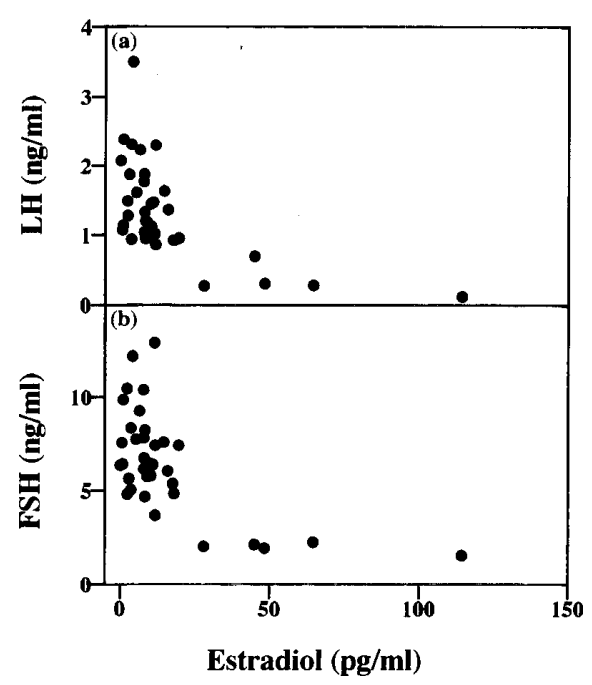

Fig. 2. Relationship between plasma concentrations of estradiol and gonadotropins. Each point represents the value obtained from the blood sample, which was taken at $1700 \mathrm{~h}$ on various days of lactation from individual animals.

completely abolished within 2 days (Fig. 3b). A preovulatory increase in both gonadotropins was observed at $1700 \mathrm{~h}$ on the $3 \mathrm{rd}$ day after weaning. Plasma levels of LH on the 4th day were relatively low; however, high levels of FSH were observed at $1100 \mathrm{~h}$ on the 4 th day after litter removal. These are characteristic features of the resumption of ovulation.

Significantly $(P<0.05)$ low levels of plasma prolactin were noted within $12 \mathrm{~h}$ after litter removal compared with mothers nursing 8 pups (Fig. 3c). Thereafter, low levels of plasma prolactin persisted through the experiment period.

A daily increase in plasma levels of progesterone was no longer apparent the day after litter removal (Fig. 3d), and significantly $(P<0.05)$ lower levels were noted at 1700 and $2300 \mathrm{~h}$ on the 2 nd day after weaning. Significantly $(P<0.05)$ high levels of progesterone were noted at $1700 \mathrm{~h}$ on the 3rd day after litter removal.

An increase in estradiol was not observed until 2 days after litter removal and then the levels increased significantly $(P<0.05)$ on the 3 rd day after weaning (Fig. 3e). Thereafter, a peak of plasma estradiol was observed at $1700 \mathrm{~h}$ on the 3 rd day after litter removal. The profiles of progesterone 


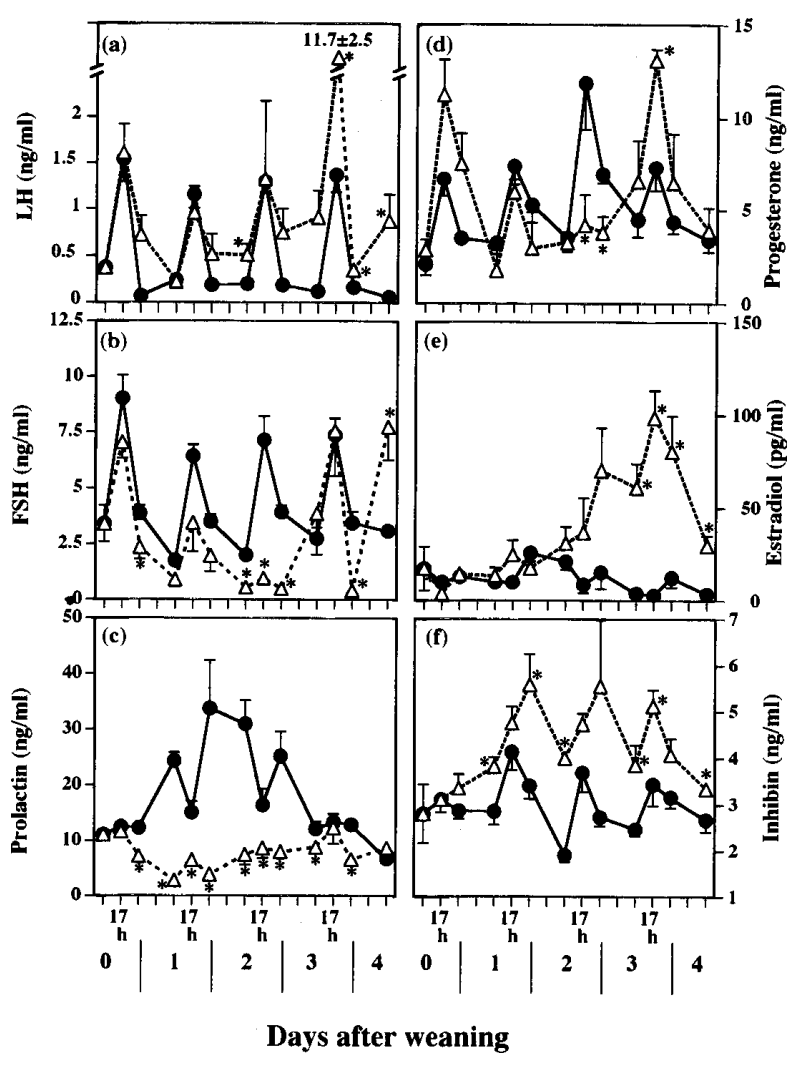

Fig. 3. Changes in plasma concentrations of (a) LH, (b) FSH, (c) prolactin, (d) progesterone, (e) estradiol, and (f) inhibin from days 10 to 14 of lactation in mothers with 8 pups $(\mathbf{O})$ or mothers weaned at 1100 $\mathrm{h}$ on day $10(\triangle)$. Each value represents mean \pm S.E.M. of five animals. *refers to a statistical difference $(P<0.05)$ in the values in mothers nursing 8 pups compared with the respective values in mothers weaned.

and estradiol on the 3rd and 4th days after litter removal are typical for days 4 and 1 of the estrous cycle in cyclic hamsters.

Plasma levels of inhibin increased within a day after weaning (Fig. 3f). Relatively high levels were then maintained in the weaned animals compared to lactating animals with 8 pups.

\section{Experiment 3. Effects of ovariectomy on the daily} increase in plasma LH and FSH (Fig. 4)

A daily increase in $\mathrm{LH}$ was unaffected by ovariectomy (Fig. 4a and 4c). On the other hand, basal levels of FSH gradually increased after ovariectomy on day 2 of lactation, compared with the values in intact lactating animals (Fig. $4 \mathrm{~b}$ and $4 \mathrm{~d}$ ). In the ovariectomized group, there were no signif-

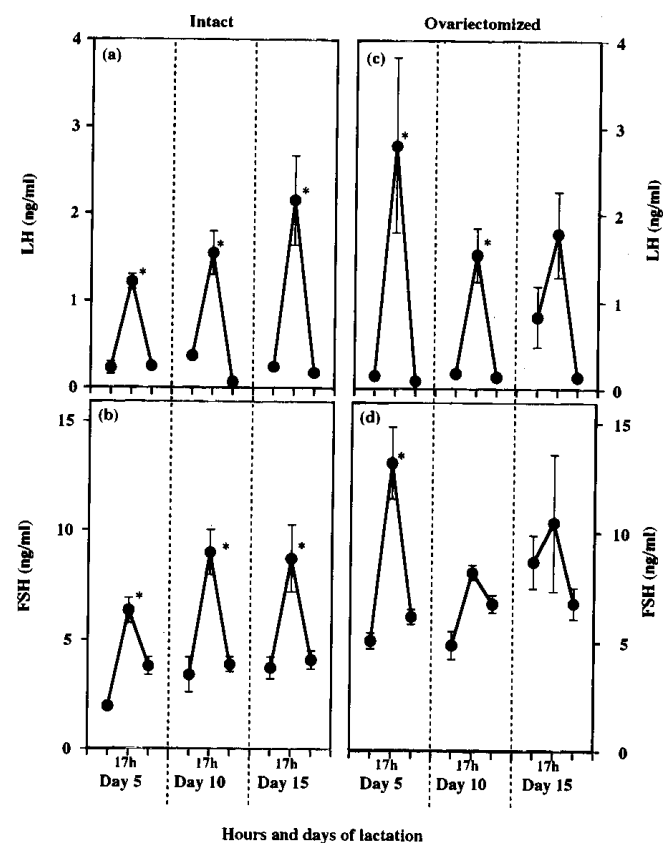

Fig. 4. Diurnal changes in plasma concentrations of $(a, c)$ LH and (b, d) FSH in lactating animals with ovaries $(a, b)$ or without ovaries $(c, d)$. Each value represents mean \pm S.E.M. of five animals. *denotes that mean daily $1700 \mathrm{~h}$ values differ significantly from mearn daily $1100 \mathrm{~h}$ values $(P<0.05)$.

icant differences among FSH levels at $1700 \mathrm{~h}, 1100$ and $2300 \mathrm{~h}$ on days 10 and 15 of lactation. Plasma concentrations of FSH noted at $1700 \mathrm{~h}$ on days 10 and 15 did not differ between ovariectomized and intact animals.

Experiment 4. Effects of an estradiol implant on daily changes in plasma levels of LH and FSH (Fig. 5)

Increases in plasma LH and FSH observed at $1700 \mathrm{~h}$ in normal lactating hamsters disappeared in the estradiol implanted animals (Fig. $5 \mathrm{a}$ and $5 \mathrm{c}$ vs. $5 \mathrm{~b}$ and $5 \mathrm{~d}$ ). However, basal LH and FSH at 1100 or $2300 \mathrm{~h}$ were unaffected. Plasma estradiol at $1700 \mathrm{~h}$ on the $3 \mathrm{rd}$ day after implantation was within the physiological range (Fig. 5f). On the other hand, estradiol was undetectable at $1700 \mathrm{~h}$ in the animals implanted with an empty tube (Fig. 5e).

Experiment 5. Effects of passive immunization against LHRH on daily changes in gonadotropins (Fig. 6)

Daily increases in both LH (Fig. 6a) and FSH 


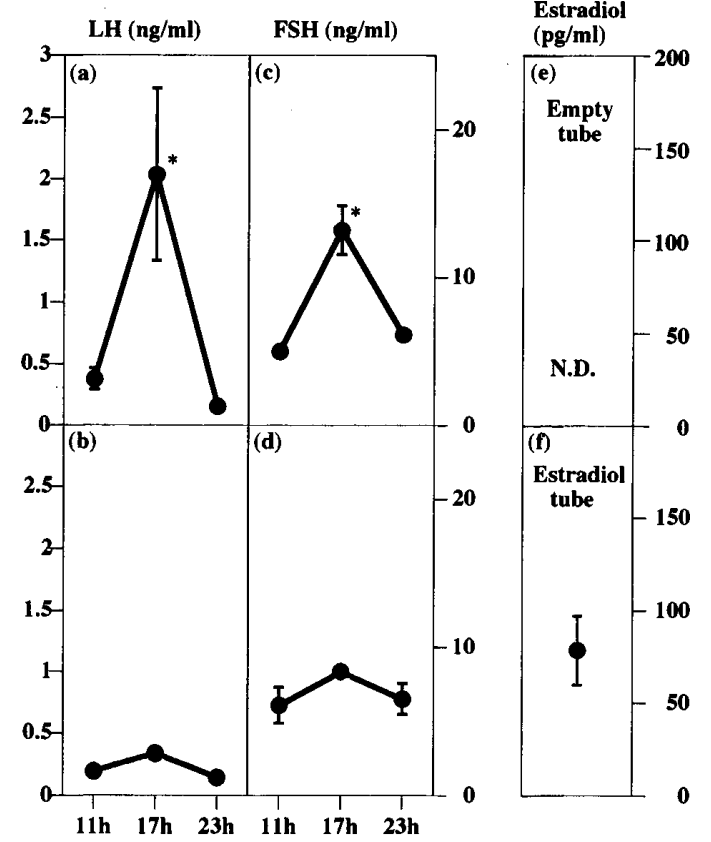

3 Days after estradiol tube implant

Fig. 5. Diurnal changes in plasma concentrations of LH $(a, c)$ and FSH $(b, d)$ in the mothers implanted with an empty tube $(a, c)$ or a tube including estradiol $(b, d)$. Plasma concentrations of estradiol at $1700 \mathrm{~h}$ on the day of the experiment in animals implanted with an empty tube (e) or a tube including estradiol (f). Each value represents mean \pm S.E.M. of five animals. *denotes that mean daily $1700 \mathrm{~h}$ values differ significantly from mean daily $1100 \mathrm{~h}$ values $(P<0.05)$.

(Fig. 6b) at $1700 \mathrm{~h}$ were completely blocked after treatment with LHRH-AS. But, basal levels of gonadotropins at $2300 \mathrm{~h}$ were unaffected by the single injection of LHRH-AS.

\section{Discussion}

The present study suggests that low plasma concentrations of estradiol are critical for a daily increase in LH and FSH during lactation in the hamster.

There were no daily increases in plasma LH and FSH in lactating hamsters nursing 2 pups during the second half of lactation, and daily increases in plasma LH and FSH disappeared within 2 days after litter removal, when plasma concentrations of estradiol increased. A daily increase in plasma LH and FSH was also completely blocked by es-
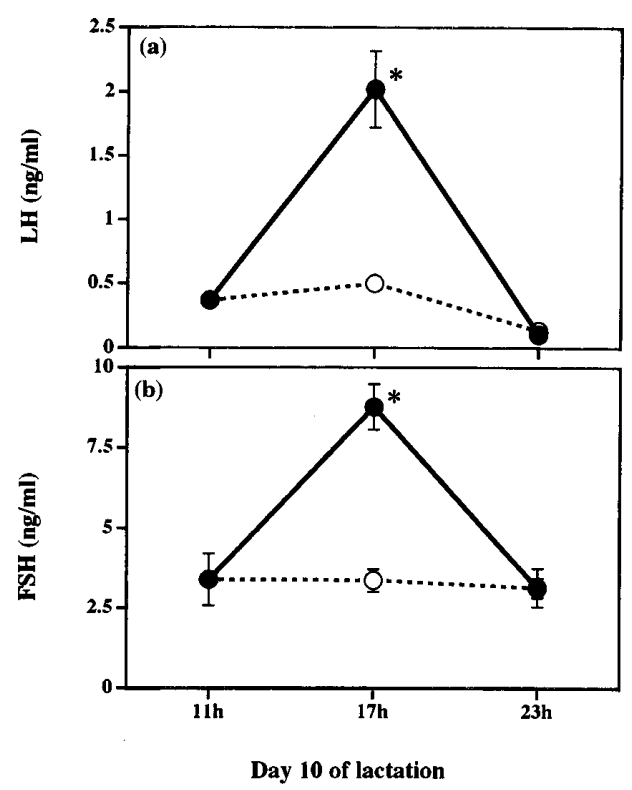

Fig. 6. Diurnal changes in plasma concentrations of (a) LH and (b) FSH in mothers treated with control serum ( ) or antiserum against LHRH (O). Each value represents mean \pm S.E.M. of five animals. *denotes that mean daily $1700 \mathrm{~h}$ values differ significantry from mean daily $1100 \mathrm{~h}$ values $(<0.05)$.

tradiol implants in lactating hamsters nursing 8 pups. Previous studies demonstrated that daily increases in plasma LH, FSH and progesterone did not occur in pregnant and pseudopregnant animals [1]. It appears that the expression of daily increase in plasma LH and FSH was also related to the levels of circulating estradiol but not to a suckling stimulus. On the other hand, a daily increase in LH and FSH was also noted in acyclic hamsters induced by short photoperiods [3] and in immature female $[8,9]$ or acyclic hamsters induced by administration of melatonin [6] or monosodium glutamate [7]. Present findings in conjunction with previous studies suggest that the suckling stimulus itself is not essential for the daily elevation of plasma levels of LH and FSH, whereas the suckling stimulus in lactating hamster may be one of the suppressing factors of gonadal function in mothers. Production of ovarian steroid hormones is limited in these anovulating hamsters as well as in lactating hamsters. Therefore, suppressed ovarian activity may be responsible for the daily increase in plasma levels of gonadotropins.

Ovariectomy did not alter the daily increase in 
plasma LH, suggesting that the presence of ovarian factors is not essential for induction of the daily plasma LH increase in lactating hamsters. This agrees with a previous study showing that a diurnal increase in plasma LH in lactating hamsters was not altered by ovariectomy [3]. However, ovariectomy increased basal levels of FSH which thus made the daily increase in plasma FSH more difficult to explain. This dichotomy between effects of ovariectomy on the secretion of LH and FSH is explicable by the presence of ovarian factors that normally suppress the basal secretion of FSH, but not LH. In the present study, plasma levels of inhibin were not high, but they were similar to basal levels observed in the cyclic hamster [12]. Inhibin is an important factor regulating the secretion of FSH in the hamster [12, 17]. Preantral follicles which do not secrete estradiol are an important source for the secretion of inhibin $[12,18]$. These findings also suggested that the disappearance of plasma inhibin following ovariectomy is responsible for the increase in basal levels of FSH.

There are no antral follicles and corpora lutea in the ovary of the lactating hamster but the interstitium is very well developed $[2,19]$. In hamsters hypophysectomized for 20 days, a single injection of $\mathrm{LH}$ results in a prompt increase in serum progesterone, presumably secreted by interstitium [20]. This suggests that the daily surge of $\mathrm{LH}$ in the lactating hamster leads to interstitial hypertrophy and stimulates an increase in progesterone.

The relationship between plasma levels of estradiol, LH and FSH at $1700 \mathrm{~h}$ in lactating animals suggests that an increase in LH and FSH at $1700 \mathrm{~h}$ takes place when circulating levels of estradiol are low. This was substantiated by the present results where the daily increase in gonadotropin were completely suppressed when exogenous estradiol was restored to lactating animals. The same phenomenon also occurs in the immature female hamster [9]; therefore, the authors concluded that increasing levels of estradiol and progesterone depress the afternoon increase in circulating levels of FSH and LH. On the other hand, estradiol induces the daily afternoon surge in the ovariectomized hamster [21]. The well known positive feedback effect of estrogen on the secretion of gonadotropins is mediated by the activation of LHRH secretion from the hypothalamus. The present findings suggested that the daily increase in gonadotropins observed in the lactating hamster may result from different mechanisms than the normal positive feedback effect of estrogen on the preovulatory LH surge on day 4 of the estrous cycle.

In the present study, administration of LHRHAS completely blocked the diurnal increase in LH and FSH, which indicated the critical role of a daily increase in LHRH. This agrees with the observation that the daily increase in plasma LH and FSH is suppressed by phenobarbital treatment which suppresses neuronal activation and hence suppresses the LHRH secretion [1]. Furthermore, these results suggested that the daily increase in plasma $\mathrm{LH}$ in lactating hamsters is caused by daily rising LHRH, which is regulated by circadian rhythm.

In conclusion, the suppression of follicular development in the lactating hamster results in low levels of plasma estradiol and consequently leads to an afternoon surge of LHRH but possibly through a different mechanism than the preovulatory gonadotropin surge in cyclic animals. The LHRH increase is regulated by circadian rhythm which in turn elevates $\mathrm{LH}$ and $\mathrm{FSH}$; the increased LH stimulates the interstitial tissue in the ovary and triggers the daily secretion of interstitial progesterone.

\section{Acknowledgment}

We wish to express our gratitude to Dr. G. S. Greenwald for reading the original manuscript and for his valuable suggestions. We are grateful to Dr. S. Raiti and the Rat Pituitary Hormone Distribution Program, NIDDK, NIH, Bethesda, MD, U.S.A. for providing RIA materials; Dr. G. D. Niswender, Animal Reproduction and Biotechnology Laboratory, Colorado State University, CO, U.S.A. for providing antisera to progesterone (GDN 337) and estradiol (GDN 244) and Teikoku Hormone, MGF Co. Ltd., Tokyo, Japan for estradiol. This work was supported in part by a grant-in-aid (The Japan-US Cooperative Science Program) from Japan Society for the Promotion of Science in Japan and a grant-in-aid (Bio Media Program) from the Ministry of Agriculture, Forestry and Fisheries (BMP-97-V-2-2-2). 


\section{References}

1. Di Pinto MN, Stetson MH. Clock-timed gonadotropin release in lactating but not pregnant hamsters. Coloq INRA 1981; 6: 83-96.

2. Greenwald GS. Histologic transformation of the ovary of the lactating hamster. Endocrinology 1965; 77: 641-650.

3. Bridges RS, Goldman BD. Diurnal rhythms in gonadotropins and progesterone in lactating and photoperiod induced acyclic hamsters. Biol Reprod 1975; 13: 617-622.

4. Blaha GC, Leavitt WW. Distribution of ovarian 5$3 \beta$ hydroxysteroid dehydrogenase activity in the golden hamster during the estrous cycle, pregnancy, and lactation. Biol Reprod 1970; 3: 362-368.

5. Seegal RF, Goldman BD. Effect of photoperiod on cyclicity and serum gonadotropin in the Syrian hamster. Biol Reprod 1975; 12: 223-231.

6. Stetson $\mathbf{M H}$, Hamilton B. The anovulatory hamster: a comparison of the effects of short photoperiod and daily melatonin injections on the induction of ovarian acyclicity. J Exp Zool 1981; 215: 173-178.

7. Donham RS, Ogilvie KM, Kerner TM, Stetson MH. Daily rhythms of luteinizing hormone and follicle-stimulating hormone persist in female hamsters sterilized by neonatal administration of monosodium glutamate. Biol Reprod 1990; 43: 392396.

8. Smith S, Stetson MH. Maturation of the clocktimed gonadotropin release mechanism in hamster: a key event in the pubertal process? Endocrinology 1980; 107: 1334-1337.

9. Donham RS, Stetson MH. The peripheral golden hamster and the transition between daily and estrous cycle hormone rhythms. Biol Reprod 1991; 44: 1108-1112.

10. Taya K, Sasamoto S. Selective release of FSH in lactating rats during the period of follicular atresia induced by the administration of antiserum to LHreleasing hormone. J Endocrinol 1988; 118: 455-464.

11. Bast JD, Greenwald GS. Serum profiles of folliclestimulating hormone, luteinizing hormone and prolactin during the estrous cycle of the hamster. Endocrinology 1974; 94: 1295-1299.
12. Kishi H, Taya K, Watanabe G, Sasamoto S. Follicular dynamics and secretion of inhibin and oestradiol-17 $\beta$ during the oestrous cycle of the hamster. J Endocrinol 1995; 146: 169-176.

13. Hamada T, Watanabe G, Kokuho T, Taya K, Sasamoto S, Hasegawa Y, Miyamoto K, Igarashi M. Radioimmunoassay of inhibin in various mammals. J Endocrinol 1989; 45: 697-704.

14. Taya K, Watanabe G, Sasamoto S. Radioimmunoassay for progesterone, testosterone and estradiol-17 $\beta$ using ${ }^{125} \mathrm{I}$-iodohistamine radioligands. Jpn J Anim Reprod 1985; 31: 186-197.

15. Korenman SG, Stevens RH, Carpenter LA, Robb M, Niswender GD. Estradiol radioimmunoassay without chromatography: procedure, validation and normal values. J Endocrinol 1974; 45: 697-704.

16. Gibori G, Antczak E, Rothchild I. The role of estrogen in regulation of luteal progesterone secretion in the rat after day of pregnancy. Endocrinology 1977; 100: 1483-1495.

17. Kishi H, Okada T, Otsuka M, Watanabe G, Taya $\mathbf{K}$, Sasamoto $\mathrm{S}$. Induction of superovulation by immunoneutralization of endogenous inhibin through the increase in the secretion of folliclestimulating hormone in the cyclic golden hamster. J Endocrinol 1996; 151: 65-75.

18. Otsuka M, Kishi H, Arai K, Watanabe G, Taya K, Greenwald GS. Temporal changes in inhibin, steroid hormones, and steroidogenic enzymes during induced follicular atresia in the hypophysectomized cyclic hamster. Biol Reprod 1997; 56 423-429.

19. Greenwald GS, Keever JE, Grady KL. Ovarian morphology and pituitary FSH and LH concentrations in the pregnant and lactating hamster. Endocrinology 1967; 80: 851-856.

20. Taya K, Greenwald GS. In vitro and in vivo ovarian steroidogenesis in the long term hypophysectomized hamster. Endocrinology 1980; 106: 1093-1098.

21. Norman RL, Blake CA, Sawyer CH. Estrogen-dependent twenty-four-hour periodicity in pituitary LH release in the female hamster. Endocrinology 1973; 93: 965-970. 